\section{A pilot study of bioaerosol reduction using an air cleaning system during dental procedures}

\author{
C. Hallier, ${ }^{1}$ D. W. Williams, ${ }^{2}$ A. J. C. Potts ${ }^{3}$ and M. A. O. Lewis ${ }^{4}$
}

IN BRIEF

- Dental procedures create bioaerosols that are a potential vector for transmission of infection in the dental surgery.

- The use of an air cleaning system both before and during dental treatment can reduce the size of bioaerosols and therefore reduce the risk of spread of infection

- Air cleaning systems may have a useful role to play in the treatment of patients, in particular those who may be immunecompromised.

\begin{abstract}
Background Bioaerosols are defined as airborne particles of liquid or volatile compounds that contain living organisms or have been released from living organisms. The creation of bioaerosols is a recognized consequence of certain types of dental treatment and represents a potential mechanism for the spread of infection. Objectives The aims of the present study were to assess the bioaerosols generated by certain dental procedures and to evaluate the efficiency of a commercially available Air Cleaning System (ACS) designed to reduce bioaerosol levels. Methods Bioaerosol sampling was undertaken in the absence of clinical activity (baseline) and also during treatment procedures (cavity preparation using an air rotor, history and oral examination, ultrasonic scaling and tooth extraction under local anaesthesia). For each treatment, bioaerosols were measured for two patient episodes (with and without ACS operation) and between five and nine bioaerosol samples were collected. For baseline measurements, 15 bioaerosol samples were obtained. For bioaerosol sampling, environmental air was drawn on to blood agar plates using a bioaerosol sampling pump placed in a standard position $20 \mathrm{~cm}$ from the dental chair. Plates were incubated aerobically at $37^{\circ} \mathrm{C}$ for 48 hours and resulting growth quantified as colony forming units $\left(\mathrm{cfu} / \mathrm{m}^{3}\right)$. Distinct colony types were identified using standard methods. Results were analysed statistically using SPSS 12 and Wilcoxon signed rank tests. Results The ACS resulted in a significant reduction $(p=0.001)$ in the mean bioaerosols $\left(\mathrm{cfu} / \mathrm{m}^{3}\right)$ of all three clinics compared with baseline measurements. The mean level of bioaerosols recorded during the procedures, with or without the ACS activated respectively, was $23.9 \mathrm{cfu} / \mathrm{m}^{3}$ and $105.1 \mathrm{cfu} / \mathrm{m}^{3}(\mathrm{p}=0.02)$ for cavity preparation, $23.9 \mathrm{cfu} / \mathrm{m}^{3}$ and $62.2 \mathrm{cfu} / \mathrm{m}^{3}(\mathrm{p}=0.04)$ for history and oral examination; $41.9 \mathrm{cfu} / \mathrm{m}^{3}$ and $70.9 \mathrm{cfu} / \mathrm{m}^{3}(\mathrm{p}=0.01)$ for ultrasonic scaling and $9.1 \mathrm{cfu} / \mathrm{m}^{3}$ and $66.1 \mathrm{cfu} / \mathrm{m}^{3}(\mathrm{p}=0.01)$ for extraction. The predominant microorganisms isolated were Staphylococcus species and Micrococcus species. Conclusion These findings indicate potentially hazardous bioaerosols created during dental procedures can be significantly reduced using an air cleaning system.
\end{abstract}

\section{INTRODUCTION}

The spread of infectious microorganisms within aerosols is recognized as a significant health risk in many vocations, including construction workers, farmers, bioscience researchers and health care workers. Many individuals working in these positions suffer from higher incidences of bioaerosolassociated infection when compared with the general population..$^{1-3}$ Not surprisingly, dental healthcare workers and their patients

\footnotetext{
Undergraduate dental student, ${ }^{2}$ Reader in Oral Microbiology, ${ }^{3}$ Consultant in Oral Pathology ${ }_{1}{ }^{4}$ Dean of School of Dentistry and Professor of Oral Medicine, School of Dentistry, Cardiff University, Heath Park, Cardiff, CF14 4XY

${ }^{*}$ Correspondence to: Prof Michael Lewis Email: lewismao@cardiff.ac.uk
}

Online article number E14

Refereed Paper - accepted 9 April 2010

DOI: 10.1038/sj.bdj.2010.975

${ }^{\circledR}$ British Dental Journal 2010; 209: E14 are also regularly exposed to bioaerosols that are likely to contain microorganisms, potential allergens or toxic substances. ${ }^{4-6}$ It is known that the generation of such bioaerosols is more likely during certain types of dental treatment. ${ }^{5}$ In addition, there is particular concern with regards to the treatment of patients who harbour respiratory viruses or bacteria, such as influenza viruses and Mycobacterium tuberculosis. ${ }^{7,8}$ Harrel and Molinari ${ }^{9}$ have also highlighted that pneumonia, tuberculosis, influenza, Legionnaire's disease and Severe Acute Respiratory Syndrome (SARS) should be regarded as being of particular concern for dentists, dental care professionals (DCPs) and patients receiving dental treatment. Since dental aerosols may contain opportunistic pathogens and create a hazardous environment, particularly for immunosuppressed patients, ${ }^{5}$ infection control precautions should aim to minimise any potential risk.

The use of a dental turbine handpiece, three-in-one syringe or ultrasonic scaling instrument has been reported to increase bioaerosol levels dramatically., ${ }^{5,9-11}$ The microbial component of these aerosols can originate from a variety of patient sources including plaque, calculus, dental materials, blood, saliva, nasopharynx ${ }^{9}$, and inadequately disinfected dental unit waterlines (DUWL). ${ }^{12}$ The latter is increasingly recognized as a potential source of infectious agents whose growth within DUWLs in the form of recalcitrant biofilms makes their removal problematic. ${ }^{13}$ While the development of bacterial air contamination during dental procedures is well recognized, ${ }^{5,9-11}$ limited information is available concerning the effectiveness of any dedicated air cleaning system (ACS), including the 


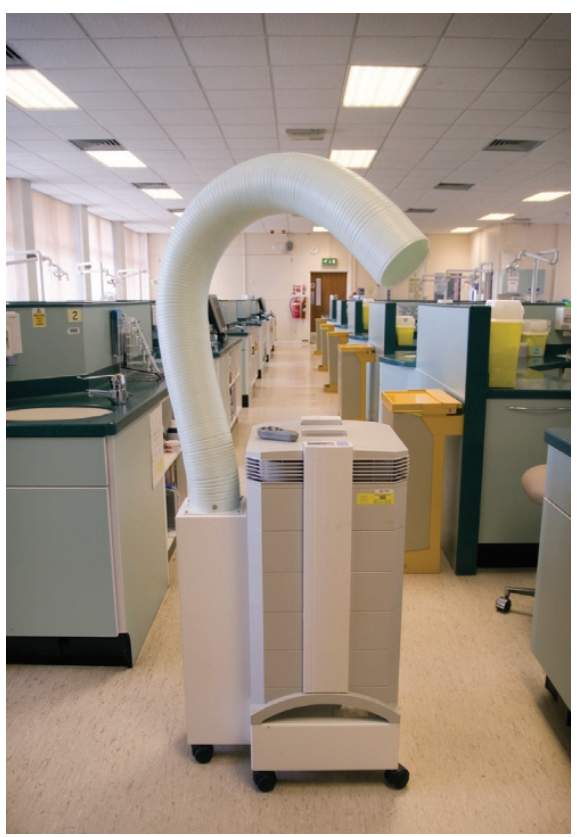

Fig. 1 The IQAir: FlexVac ${ }^{\mathrm{TM}}$ air cleaning system used in this study

IQAir: FlexVac ${ }^{\mathrm{TM}}$ equipment. The IQAir system (Fig. 1) comprises a 1,500 mm long flexible polypropylene plastic suction duct (125 mm diameter) that firstly directs air through a combination of High Efficiency Particulate Air (HEPA) pre-filters which retain particles less than $0.3 \mu \mathrm{m}$ in size (which includes bacteria and many types of virus). A second filtration stage involves four cylinder gas filter cartridges, which remove mercury vapour, formaldehyde, glutaraldehyde and odours. The final filtration stage comprises of an electrostatically charged post-filter.

The aims of the present study were to measure the levels of bioaerosol associated with dental procedures and to determine if these could be reduced in the local environment by use of the IQAir system both before and during certain types of dental procedure.

\section{MATERIALS AND METHODS}

\section{Bioaerosol sampling}

A Buck Bio-Culture ${ }^{\mathrm{TM}}$ (Model B30120; A. P. Buck, Inc) sampling pump was used to collect air samples on to blood agar plates (Lab $\mathrm{M}^{\mathrm{TM}}$, Diagnostics Group Plc., Bury) supplemented with 5\% (v/v) defibrinated sheep blood (TCS Biosciences Ltd., Buckingham). The sampling pump was located $20 \mathrm{~cm}$ away from the dental chair, since this distance has previously been reported to be associated with high bioaerosol level. ${ }^{11}$ The sampling pump was run continuously during patient treatment, with agar plates replaced every $10 \mathrm{~min}$. In all cases, the sampling pump was calibrated to $2.7 \mathrm{~mm}$ of water pressure at a flow rate of $100 \mathrm{~L} /$ minute every $30 \mathrm{~min}$ during air sampling.

Air sampling was performed during four dental procedures undertaken in three separate clinics of the University Dental Hospital and School in Cardiff. For each dental procedure, testing was performed on separate days. Baseline sampling, to serve as a control, was performed during the weekend, when no dental treatment was being undertaken and a total of 15 separate air samples were obtained.

The IQAir Air Cleaning System (ACS) was activated 1 hour before samples were taken and was operated continuously at $500 \mathrm{~m}^{3} /$ hour. History and oral examination, using a standard probe and a mirror, was assessed in Clinic 1. The same clinic was used for the assessment of patients undergoing cavity preparation using a high-speed dental handpiece. Ultrasonic scaling, in conjunction with High Volume Aspiration (HVA), was assessed in Clinic 2, while tooth extraction under local anaesthesia was assessed in Clinic 3. All baseline and procedure sampling was performed with the clinic windows closed and no air conditioning systems or fans on. The room temperature in all three clinical areas was between $21-24^{\circ} \mathrm{C}$.

Clinic 1 and Clinic 2 were large open multi-chair clinical areas, while Clinic 3 was a single-chair room. The study involved eight patients (two patients for each treatment episode, thereby allowing comparison of bioaerosols with and without the ACS in operation) treated by eight dental students in an attempt to minimise patient and operator bias. Sampling was undertaken in the same dental units in each of the three clinics at baseline and during the four procedures. The ACS and sampling pump were placed in the same position throughout the study. The blood agar plates were replaced every $10 \mathrm{~min}$ in the sampling pump during the course of each treatment procedure.

\section{Identification of isolated microorganisms}

All plates were incubated aerobically at $37^{\circ} \mathrm{C}$ for 48 hours. Bacterial colonies were counted and a Gram stain performed on representative colonies. ${ }^{14}$ Growth was expressed as colony forming units per unit volume (cfu/m $\mathrm{m}^{3}$ ) as previously described by Monarca et al..$^{15}$ and Grenier. ${ }^{5}$

\section{Statistical analysis}

The data was subjected to non-parametric analysis using the Statistical Package for Social Sciences (SPSS 12) program. Wilcoxon signed rank tests were used for pairwise comparisons to test the principal hypothesis that the ACS caused a significant reduction in the level of bacterial aerosol.

\section{RESULTS}

Bioaerosol levels were increased from baseline in each of the clinics during all of the procedures as shown by the boxplots in Figure 2 and Table 1. The increase was greatest during cavity preparation (23.9 $\mathrm{cfu} / \mathrm{m}^{3}$ compared to $105.1 \mathrm{cfu} / \mathrm{m}^{3}$ ) and during tooth extraction $\left(9.1 \mathrm{cfu} / \mathrm{m}^{3}\right.$ compared to $66.1 \mathrm{cfu} / \mathrm{m}^{3}$ ).

Activation of the ACS in each of the clinics, with no dental procedure being performed, produced a significant $(\mathrm{p}<0.05)$ reduction of between 72 - 87\% in baseline bioaerosol levels, with a reduction to a mean bacterial count of $5.6 \mathrm{cfu} / \mathrm{m}^{3}$ in Clinic $1,5.3 \mathrm{cfu} / \mathrm{m}^{3}$ in Clinic 2 and $2.5 \mathrm{cfu} /$ $\mathrm{m}^{3}$ in Clinic 3 (Table 1).

Assessment of bioaerosol levels during the four dental procedures with the ACS in operation revealed a significant reduction in bacterial levels for all four procedures (Table 1, Fig. 3) with this reduction being statistically significant for cavity preparation ( $p=0.018)$, ultrasonic scaling $(p=0.027)$ and tooth extraction $(p=0.036)$. The reduction in the bioaerosol associated with history and examination was not significant.

\section{DISCUSSION}

A safe working environment is an essential aspect of the delivery of dental healthcare. Microorganisms within the mouth and respiratory tract of patients can be mobilised in the form of bioaerosols during dental procedures and this represents a potential infection risk within the clinic. Specific concern has been raised in relation to the possible transmission of microorganisms responsible for tuberculosis, pneumonia and influenza, especially if 
immunocompromised patients are being treated..$^{9}$ High-speed dental handpieces and ultrasonic scalers are known to produce airborne particles with microbial components originating from a number of sources within the mouth. ${ }^{5}$ In addition to microorganisms from the patient, the water cooling system used in conjunction with these instruments can be a source of bioaerosol infection. One caveat when interpreting the findings from the present study is therefore the possible influence of differing levels of microbial contamination within the DUWLs of the dental chairs used. Previous investigation has shown that the age of dental chairs within the same hospital and employing the same water supply is not an influencing factor for water contamination levels, ${ }^{16}$ although the model of the chair could have an effect. ${ }^{17}$ In this present study the make and models of the chairs were the same. The resultant bioaerosol will also be influenced by the temperature, humidity and level of ventilation in the surgery. Finally, the potential risk that the bioaerosol presents to an individual will depend on their immune status. ${ }^{5}$

It is not surprising that a range of approaches and practices have been developed in an effort to reduce the impact of bioaerosols in the dental setting. The use of high-volume wide-bore aspiration and pre-procedural antiseptic mouth rinse have both been demonstrated to reduce the risk of airborne spread of infection. ${ }^{9}$ Aspiration can reduce airborne bacterial contamination by more than $90 \%{ }^{7}$ while rinsing using $0.01 \%$ chlorhexidine mouthwash for one minute has also been shown to significantly reduce the bacterial count in the air. ${ }^{9}$ A mask, eye protection and gloves protect against contamination caused by splatter droplets or direct contact from the operative site. However, even the best quality masks only filter between $60-95 \%$ of airborne microorganisms and are subject to leakage, if not well-fitting. ${ }^{9}$ In addition, any protection from airborne elements ceases when the mask is removed post-procedure. ${ }^{7}$ This is of concern since bioaerosols can persist in the air for up to 30 minutes after the procedure has been completed.$^{18}$ The use of a rubber dam during dental procedure has been shown to eliminate virtually all microorganisms in the air arising from blood or saliva within the mouth. ${ }^{9}$ When using rubber dam the

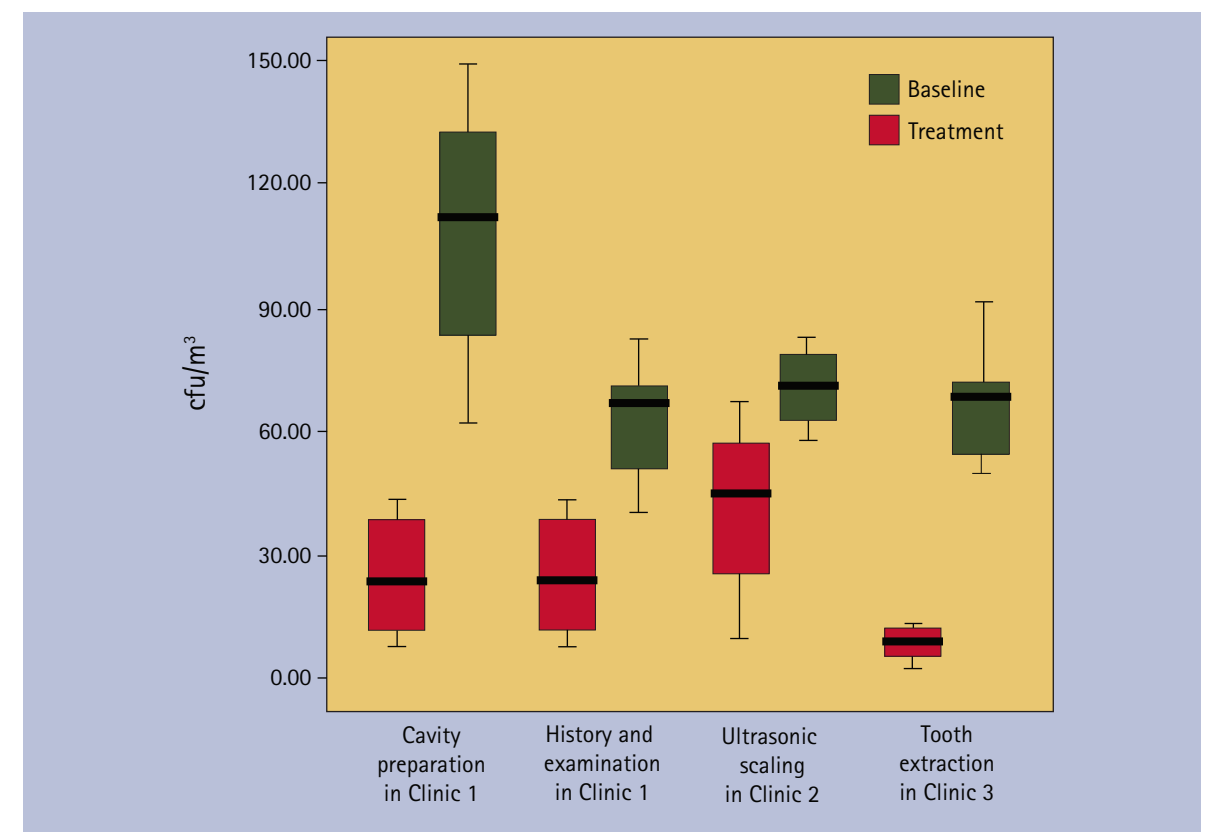

Fig. 2 Level of bioaerosols (colony forming units per cubic metre, $\mathrm{cfu} / \mathrm{m}^{3}$ ) at base line and during four types of dental treatment

Table 1 Level of bioaerosol at baseline and during four dental procedures with and without an air cleaning system (ACS) activated

\begin{tabular}{|c|c|c|c|c|c|}
\hline \multirow[t]{2}{*}{ Location } & \multirow[t]{2}{*}{ Procedure } & \multicolumn{2}{|c|}{$\begin{array}{l}\text { Mean bacterial count at } \\
\text { baseline } \\
\mathrm{cfu} / \mathrm{m}^{3}\end{array}$} & \multicolumn{2}{|c|}{$\begin{array}{l}\text { Mean bacterial count } \\
\text { during procedure } \\
\mathrm{cfu} / \mathrm{m}^{3}\end{array}$} \\
\hline & & ACS off & ACS on & ACS off & ACS on \\
\hline Clinic 1 & $\begin{array}{l}\text { No procedure } \\
\text { Cavity preparation } \\
\text { History and examination }\end{array}$ & 23.9 & $5.6^{*}$ & $\begin{array}{l}105.1^{* *} \\
69.2^{* *}\end{array}$ & $\begin{array}{l}38.4^{* * *} \\
59.8\end{array}$ \\
\hline Clinic 2 & $\begin{array}{l}\text { No procedure } \\
\text { Ultrasonic scaling }\end{array}$ & 41.9 & $5.3^{*}$ & $70.9^{* *}$ & $38.5^{* * *}$ \\
\hline Clinic 3 & $\begin{array}{l}\text { No procedure } \\
\text { Tooth extraction }\end{array}$ & 9.1 & $2.5^{*}$ & $66.1^{* *}$ & $37.0^{* * *}$ \\
\hline \multicolumn{6}{|c|}{$\begin{array}{l}\text { cfu/m } / \mathrm{m}^{3}=\text { colony forming units per cubic metre } \\
{ }^{*} \text { significant }(P=0.01) \text { decrease in baseline bacterial counts with ACS on } \\
{ }^{* * *} \text { significant }(P<0.05) \text { increase in bacterial counts for procedures compared with baseline (ACS off) } \\
{ }^{*} \text { significant }(P<0.05) \text { decrease in bacterial counts for procedures with ACS on compared with ACS off }\end{array}$} \\
\hline
\end{tabular}

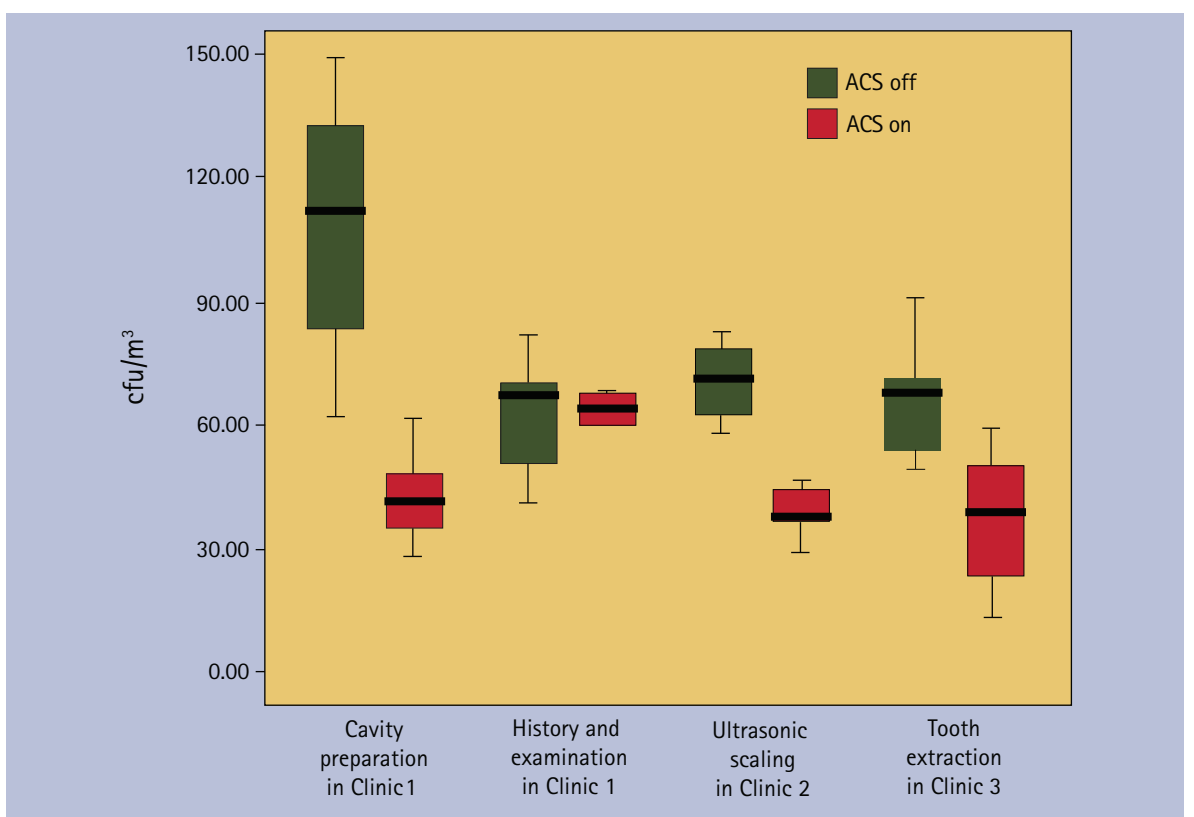

Fig. 3 Level of bioaerosols (colony forming units per cubic metre, $\mathrm{cfu} / \mathrm{m}^{3}$ ) during four types of dental treatment with an air cleaning system (ACS) turned on and turned off 
primary source of airborne contamination is the water supply from the dental instruments. The Centre for Disease Control (CDC) currently advocates the use of a rubber dam, where possible, together with the routine use of a high volume aspiration. However, since dental procedures may be performed without the help of an assistant, the use and efficacy of aspiration can be variable.

The findings of the present study have confirmed that bioaerosol levels were increased during dental procedures. The fact that bioaerosol sampling was undertaken for each treatment procedure on separate days ensured that residual bioaerosol from the control (without ACS in operation) and test (with ACS operation) sampling would not influence measurements. The size of increase in bioaerosol level was dependent on the type of procedure being performed. A significant increase in bioaerosol level was encountered during cavity preparation, ultrasonic scaling and tooth extraction. All these procedures are invasive and therefore generation of bioaerosol was not unexpected. In the present study, the highest level of bioaerosol occurred during cavity preparation, which contrasts with the findings of Harrel and Molinari, ${ }^{9}$ who found that use of an ultrasonic scaler produced the highest levels of airborne contamination. Micik et al. ${ }^{11}$ found that air-turbine hand pieces, when used with air-water spray coolant, generated 20 times greater number of bacteria than air spray alone. With regard to scaling, Harrel et al. ${ }^{19}$ stated that ultrasonic scaling produced higher aerosols when compared to hand scaling. The design of the relative clinics might have been an influencing factor on bioaerosol levels, as it could be hypothesised that large open-plan multi-chair clinics (Clinics 1 and 2 in the present study) would provide greater bioaerosol levels than a single chair clinic (Clinic 3) due to more air disturbance and potentially greater levels of bioaerosols from other locally performed procedures in the open-plan clinics. This was not however apparent given the higher recorded bioaerosol obtained from the extraction procedure (Clinic 3) compared with the history and oral examination procedure undertaken in Clinic 1. A further potential additional variable that needs to be considered is the possible variation in the levels of DUWL contamination which could adversely affect the loading of dental aerosols from the different dental units.

While there is no international standard stipulated for an acceptable level of bioaerosol in dental clinics, Whyte et al. ${ }^{20}$ proposed that for an ultraclean operating room the mean bacteria-carrying particles should not exceed more than 10 per $\mathrm{m}^{3}$. Interestingly these levels were achieved in all three clinics at baseline when the ACS was activated.

The results of the present study also provide the first evidence that an ACS can significantly reduce the bioaerosol load during dental procedures. However, on no occasion was the level reduced to that encountered at baseline. Regardless of this, it can be concluded here that the IQ Air Flex Vac ${ }^{\mathrm{TM}}$ ACS was efficient at reducing the mean bacterial aerosols within a dental clinic. While the use of an ACS and such a reduction in bioaerosol may not be required in every setting, such equipment has been shown here, as a general principle, to provide a safer working environment. In this respect some clinics may wish to adopt such a standard of healthcare delivery. The use of an ACS could have an important specific role to play in the treatment of medically compromised individuals in specialist dental facilities.

We are grateful to Mr Jonathon Wells (Air Science) for the provision of the Buck Bio-pump. We are also indebted to those dental students, staff and patients who allowed air sampling to be done during treatment provision.

1. Skórska C, Sitkowska J, Krysińska-Traczyk E,
Cholewa G, Dutkiewicz J. Exposure to airborne microorganisms, dust and endotoxin during processing of peppermint and chamomile herbs on farms. Ann Agric Environ Med 2005; 12: 281-288.

2. Epling C A, Rose CS, Martyny J W et al. Endemic work-related febrile respiratory illness among construction workers. Am J Ind Med 1995; 28: 193-205.

3. Douwes J, Thorne P, Pearce N, Heederik D. Bioaerosol health effects and exposure assessment: progress and prospects. Ann Occup Hyg 2003; 47: 187-200.

4. Al Maghlouth A, Al Yoursef Y, Al Bagieh N. Qualitative and quantitative analysis of bacterial aerosols. J Contemp Dent Pract 2004; 5: 91-100.

5. Grenier D. Quantitative analysis of bacterial aerosols in two different dental clinic environments. Appl Environ Microbiol 1995; 61: 3165-3168.

6. Jakush J. Infection control in the dental office: a realistic approach. J Am Dent Assoc 1986; 112: 458-468.

7. Harrel S K. Airborne spread of disease - the implications for dentistry. J Calif Dent Assoc 2004; 32: 901-906.

8. Leggat P A, Kedjarune U. Bacterial aerosols in the dental clinic: a review. Int Dent J 2001; 51: 39-44.

9. Harrel S K, Molinari J. Aerosols and splatter in dentistry: a brief review of the literature and infection control implications. J Am Dent Assoc 2004; 135: 429-437

10. Pagniano P R, Scheid R C, Rosen S, Beck F M. Airborne microorganisms collected in a preclinical dental laboratory. J Dent Educ 1985; 49: 653-655.

11. Micik R E, Miller R L, Mazzarella M A, Ryge G. Studies on dental aerobiology. I. Bacterial aerosols generated during dental procedures. J Dent Res 1969; 48: 49-56.

12. Walker J T, Bradshaw D J, Finney M et al. Microbiological evaluation of dental unit water systems in general dental practice in Europe. Eur $J$ Oral Sci 2004; 112: 412-418

13. Coleman D C, O'Donnell M J, Shore A C, Russell R J. Biofilm problems in dental unit water systems and its practical control. J App/ Microbiol 2009; 106: 1424-1437.

14. Murray P R, Baron E J, Pfaller M A, Tenover F C Yolken R H. Manual of Clinical Microbiology. 7th ed. Washington D.C: ASM Press, 1999.

15. Monarca S, Grottolo M, Renzi D et al. Evaluation of environmental bacterial contamination and procedures to control cross infection in a sample of Italian dental surgeries. Occup Environ Med 2000; 57: 721-726.

16. Smith A J, McHugh S, McCormick L, Stansfield R, McMillan A, Hood J. A cross sectional study of water quality from dental unit water lines in dental practices in the West of Scotland. Br Dent. J 2002; 193: 645-648.

17. Challacombe S J, Fernandes L L. Detecting Legionella pneumophila in water systems: a comparison of various dental units. J Am Dent Assoc 1995; 126: 603-608.

18. Hinds W C. Aerosol Technology: Properties, Behavior, and Measurement of Airborne Particles. 2nd ed. New York: John Wiley \& Sons, 1999.

19. Harrel S K, Barnes J B, Rivera-Hidalgo F. Aerosol and splatter contamination from the operative site during ultrasonic scaling. J Am Dent Assoc 1998; 129: 1241-1249.

20. Whyte W, Lidwell O M, Lowbury E J, Blowers R. Suggested bacteriological standards for air in ultraclean operating room. J Hosp Infect 1983; 4: 133-139. 